\title{
Patient's Reasons for Not Disclosing Depression
}

Ann Fam Med 2011;9:iii. doi:10.1370/afm.1320.

$\mathrm{T}$ The Annals of Family Medicine encourages readers to develop a learning community of those seeking to improve health care and health through enhanced primary care. You can participate by conducting a RADICAL journal club and sharing the results of your discussions in the Annals online discussion for the featured articles. RADICAL is an acronym for Read, Ask, Discuss, Inquire, Collaborate, Act, and Learn. The word radical also indicates the need to engage diverse participants in thinking critically about important issues affecting primary care and then acting on those discussions. ${ }^{1}$

\section{HOW IT WORKS}

In each issue, the Annals selects an article or articles and provides discussion tips and questions. We encourage you to take a RADICAL approach to these materials and to post a summary of your conversation in our online discussion. (Open the article online and click on "TRACK Comments: Submit a response.") You can find

discussion questions and more information online Alm at: http://www.AnnFamMed.org/AJC/.

\section{CURRENT SELECTION}

\section{Article for Discussion}

Bell RA, Franks P, Duberstein PR, et al. Suffering in silence: reasons for not disclosing depression in primary care. Ann Fam Med. 2011;9(5):439-446.

\section{Discussion Tips}

Depression can be challenging to detect, and it is easy to blame patients for framing their visits in ways that make detection more difficult. More challenging is to try to understand depression from the patients' point of view and to consider the effects of our own behavior in creating an environment in which patients are comfortable sharing their deep concerns, even if those concerns challenge our medical model. This issue's journal club article gives us data to inform our efforts to create an open environment for patients to share depressive symptoms.

\section{Discussion Questions}

- What questions are asked by this study and why does it matter? How was theory used to frame the questions?

- How does this study advance beyond previous research and clinical practice on this topic?

- How strong is the study design for answering the question?

- To what degree can the findings be accounted for by:

1. How patients were selected, excluded, or lost to follow-up?

2. How the main variables were measured?

3. Confounding (false attribution of causality because 2 variables discovered to be associated actually are associated with a 3 rd factor)?

4. Chance?

5. How the findings were interpreted?

- How comparable is the study sample to similar patients in your practice? What is your judgment about the transportability of the findings?

- What are the main study findings?

- What reflections do you have on (1) the factors that patients say affect their disclosure of depressive symptoms, and (2) the characteristics of patients less likely to disclose depression? How might our/your approach to patients in general, and to the diagnosis and treatment of depression in particular, help create an environment in which patients feel safe disclosing depressive symptoms?

- How might this study change your practice? Policy? Education? Research?

- Could patients in your practice be engaged in interpreting or helping your practice to use the findings? How?

- What are the next steps in interpreting or applying the findings to change practice?

- What researchable questions remain?

\section{References}

1. Stange KC, Miller WL, McLellan LA, et al. Annals Journal Club: It's time to get RADICAL. Ann Fam Med. 2006;4(3):196-197. http://annfammed.org/cgi/content/full/4/3/196. 